\title{
PARATUBERCULOSE EM PEQUENOS RUMINANTES DOMÉSTICOS
}

\section{D.G.G. Schwarz, I.A. Carvalho, P.A.G. Pietralonga, A.C.S. Faria, M.A.S. Moreira}

Universidade Federal de Viçosa, Departamento de Veterinária, Setor de Medicina Veterinária Preventiva e Saúde Pública, Laboratório de Doenças Bacterianas, Av. Ph Rolfs, s/nº, CEP 36570-000, Viçosa, MG, Brasil. E-mail: masm@ufv.br

\section{RESUMO}

\begin{abstract}
Mycobacterium avium subesp. paratuberculosis (MAP) é o agente etiológico da paratuberculose em ruminantes domésticos e silvestres. Em caprinos e ovinos causa uma enterite granulomatosa crônica com emagrecimento progressivo seguido de morte, raramente a diarreia é observada. Nesse aspecto, a doença é considerada uma ameaça mundial aos rebanhos, pois pode permanecer no estádio subclínico por anos, manifestando perdas indiretas na produção animal e na disseminação do agente. Além disso, existem relatos da possível relação de MAP com a doença de Crohn, determinando, assim, a sua relevância na saúde pública. O Brasil não dispõe de dados quantificando as reais perdas produtivas nos rebanhos acometidos pela doença, e poucas informações do comprometimento de caprinos e ovinos no país são relatadas. Assim, este artigo busca revisar a paratuberculose em pequenos ruminantes domésticos.
\end{abstract}

PALAVRAS-CHAVE: Mycobacterium avium subesp. paratuberculosis, ovinos, caprinos.

\section{ABSTRACT}

PARATUBERCULOSIS IN SMALL DOMESTIC RUMINANTS. Mycobacterium avium subsp. paratuberculosis (MAP) is the causative agent of paratuberculosis in domestic and wild ruminants. In sheep and goats it causes a chronic granulomatous enteritis with progressive emaciation and death, diarrhea rarely being observed. In this aspect, the disease is considered a worldwide threat to livestock, as it may remain subclinical for years, with indirect losses in production and agent dissemination. In addition, there are reports of a possible relationship with the agent of Crohn's disease, so it is also of relevance to public health. Brazil does not have any data quantifying the actual production losses in herds affected by the disease, and few details of the involvement of goats and sheep in the country have been reported. Thus, this paper aims to review the occurrence of paratuberculosis in flocks of domestic small ruminants.

KEY WORDS: Mycobacterium avium subsp. paratuberculosis, sheep, goats.

A paratuberculose é uma doença bacteriana contagiosa crônica do trato intestinal que afeta predominantemente ruminantes domésticos e silvestres (CHIODINI et al., 1984; ClARKE, 1997; Ayele et al., 2001; MотA et al., 2010), causada pelo Mycobacteriumavium subesp. paratuberculosis (MAP), da família Mycobacteriaceae. Estes são bastonetes aeróbicos, imóveis, catalase positiva, sendo considerados Gram positivos (TIMms et al., 2011). Por apresentarem grande quantidade de ácido micólico e lipídios na parede celular, coram-se melhor pela técnica de Ziehl-Neelsen, onde a fucsina carbólica se liga aos lipídeos da parede celular, resistindo ao descorante álcool-ácido, sendo classificados como bacilos álcool-ácido resistentes (BAAR) (QUINN et al., 2005). Essa característica lipídica em sua parede celular confere elevada resistência no meio ambiente. Whittington et al. (2004) demonstraram que MAP pode permanecer viável em solos sombreados por mais de 55 semanas, sendo resistentes à maioria dos desinfetantes comumente utilizados (ColLINS, 2003). Recentemente, foi verificado que MAP pode também utilizar a esporulação como um mecanismo para persistir em condições desfavoráveis, tais como as encontradas no solo e ambientes aquáticos (LAMONT et al., 2012). Além disso, pesquisas têm demonstrado que MAP pode resistir a altas temperaturas e permanecer viável após o processo de pasteurização (GRANT et al., 2002; Ayele et al., 2005)

A primeira descrição da doença ocorreu na Alemanha por JoHNE; FROTHINGHAM (1895) quando isolaram BAAR do intestino de um bovino com enterite granulomatosa crônica. Em pequenos ruminantes, CHIODINI (1993) expôs que os primeiros relatos foram feitos em 1911, na espécie ovina por Stockman e, em 1924, na caprina. Em 1912, o agente recebeu o nome 
de Mycobacteriumenteritis chronicaepseudotuberculosis bovis johne (TwORT; INGRAM, 1912). Por apresentar similaridades com a tuberculose intestinal, em 1923, a doença de Johne também foi denominada paratuberculose, na qual o agente etiológico passou a ser chamado Mycobacterium paratuberculosis (BERGEY et al., 1923). Após resultados de estudos genômicos e fenotípicos demonstrando similaridades com o complexo Mycobacterium avium, THorel et al. (1990) propuseram alteração da nomenclatura do agente para M. avium subesp. paratuberculosis (MAP), nome aceito e usado até os dias atuais.

A paratuberculoseédistribuída por todo o mundo e sua prevalência varia de acordo com a região e país. Em Missouri, EUA, um estudo revelou soropositividade em 5\% dos bovinos testados (THORNE; HARDIN, 1997). No entanto, estima-se que $68,1 \%$ das fazendas leiteiras desse país possuam animais infectados por MAP (ANimAL..., 2008). Na Europa, a prevalência em bovinos foi estimada em aproximadamente $20 \%$, sendo de pelo menos 3 a $5 \%$ em vários países (NielsEN; TofT, 2009). Na região de Madrid, Espanha, verificou-se que $11,7 \%$ dos bovinos testados foram soropositivos (MaINAR-JAIME; VÁZQUEZ-BOLAND, 1998). Na Bélgica, $18 \%$ dos rebanhos não vacinados e $0,87 \%$ dos animais testados apresentaram soropositividade para MAP(BOELAERT et al., 2000). Na Itália, foram verificadas prevalências de 2,6\% na região de Lombardy e $4,0 \%$ na região de Veneto (Pozzato et al., 2011). Por outro lado, na Austrália, a prevalência varia entre 9 a 22\% (MANning; Collins, 2001).

No Brasil, a primeira identificação da doença foi registrada em 1915 por Octávio Dupont em bovinos da raça Flamenga importados da Bélgica para o Rio de Janeiro (Dupont, 1915). Desde então, pensou-se que a doença era exótica e os casos apenas restritos aos animais importados. Contudo, DARCORSO FILHO et al. (1960) identificaram a doença em bovinos nascidos e criados no Brasil. Registros subsequentes da enfermidade foram verificados em diferentes estados brasileiros (PoRTUGAL et al., 1979; RAMOs et al., 1986; DRIEMEIER et al., 1999; CARVAlHo et al., 2009; COSTA et al., 2010), demonstrando que a doença ocorre em rebanhos nacionais. Os métodos para determinar a prevalência da paratuberculose em diferentes estados brasileiros ainda são fundamentados em diferentes metodologias, apresentando resultados que não possibilitam uma avaliação total do acometimento dos rebanhos no país. Contudo, estudos revelaram uma prevalência de 37,9\% no Estado de São Paulo (Fonseca et al., 1999), 30\% no Estado do Rio de Janeiro (Ristow et al., 2007), 60,24\% em Goiânia (ACYPRESTE et al., 2005), 45,51\% no Mato Grosso do Sul (Rivera, 1996) e, no Espírito Santo, Costa et al. (2010) fizeram um levantamento sorológico constatando positividade em $11,4 \%$ dos animais avaliados. Em pequenos ruminantes domésticos, a doença foi reproduzida experimentalmente em ovinos por SILVA (1968) e em caprinos por Poester; RAMOS (1994) através de inoculação via oral de emulsões de linfonodos mesentéricos e/ou mucosa intestinal de bovinos acometidos pela paratuberculose. $\mathrm{Na}$ Paraíba, OliveIra etal. (2010) comprovaram a infecção natural de MAP em caprinos e ovinos, através das lesões histopatológicas características da doença e pela presença de BAAR no citoplasma de macrófagos e linfócitos. Recentemente, um estudo realizado em 14 municípios desse mesmo estado, revelou que dentre os animais testados $44,96 \%$ caprinos e $54,08 \%$ ovinos foram positivos sorologicamente para MAP (MedeIros et al., 2012).

A ingestão de alimentos ou água contaminados por fezes de animais acometidos pelo MAP firma-se como a principal forma de transmissão (RADOSTITS et al., 2002), embora se tenham relatos de transmissão vertical e transmamária em ovinos (LAMBETH et al., 2004).

Na espécie bovina, observa-se que os animais menores de quatro meses de idade são os mais suscetíveis à infecção por MAP, embora manifestem os sinais clínicos somente após dois anos de idade (Ayele et al., 2001). Entretanto, para o surgimento dos sinais clínicos em animais adultos, há necessidade de altas concentrações e um longo período de incubação do agente no hospedeiro (LARSEN et al., 1975). Assim, acredita-se que fato semelhante de suscetibilidade ocorra nas espécies ovina e caprina. Dada essa suposição, deve-se considerar a maior chance de infecções em animais jovens, levando-se em conta a existência de estudos comprovando a presença de MAP no leite e/ ou no colostro de vacas, ovelhas e cabras com infecção clínica ou subclínica (SWEENEY et al., 1992a; Nielsen et al., 2008; CARVALHO et al., 2009; DiMARELI-MALLI, 2010).

Além dos fatores associados à transmissão vertical, MAINAR-JAime; VÁzQUEZ-Boland, (1998) verificaram o aumento no risco da ocorrência da paratuberculose em caprinos e ovinos quando esses foram criados em rebanhos entre 200 a 400 animais em manejo intensivo; condição que possibilita o potencial contato com fezes oriundas de animais infectados, presentes no local. Além disso, a inclusão de novos animais nos rebanhos e a criação conjunta de caprinos e ovinos também aumentou as chances de ocorrência da doença nos rebanhos (AL-MAJALI et al., 2008). Este fato também foi verificado quando OLIVEIRA et al. (2010) comprovaram a infecção por MAP em rebanhos ovinos e caprinos criados de forma conjunta no Brasil.

Nos caprinos e ovinos, a principal manifestação clínica é o emagrecimento progressivo sendo que, ao contrário do que se constata com frequência em bovinos, a diarreia raramenteé observada (STEHMAN; Shulaw, 1996; OliveIra et al., 2010). Fatores como a 
deficiência nutricional, alta produção de leite, presença de parasitos, infecções virais ou bacterianas e estresse no transporte dos animais podem influenciar no surgimento dos sinais clínicos (ST-JeAN; JERINGAN, 1991) e acelerar o curso da enfermidade. Independentemente da evolução clínica aparente dos animais infectados, estes eliminam maior quantidade do micro-organismo pelas fezes e menor quantidade pelo leite (LARSEN et al., 1975).

Uma vezque o ruminanteingere o micro-organismo, o animal menos suscetível pode eliminar MAP pelas fezes sem que ocorra a infecção, através de um fenômeno chamado "pass-through" (SWEENEY et al., 1992b). Por outro lado, animais mais suscetíveis podem se tornar infectados ao apresentar o agente na forma intracelular e eliminar também MAP pelas fezes, (NIELSEN; TofT, 2008), seguido pelas manifestações dos sinais clínicos. O desenvolvimento da doença em animais infectados pode ser divido em três fases distintas, segundo Cосітo et al. (1994): na fase I têm-se a infecção (forma subclínica) onde não ocorre excreção considerável de bactérias pelas fezes; a fase II é caracterizada pela infecção e excreção subclínica de MAPvia fezes, bem como pelo número crescente de micro-organismos no intestino. Na fase III, da infecção, tem-se a presença de diarreia crônica (mais frequente em bovinos), na qual o agente é localizado intracelularmente, e surgem os sinais clínicos que potencializam a diminuição da captação de nutrientes pelo intestino e resultam no emagrecimento progressivo.

Em ruminantes deum modo geral, ao ser ingerido, $\mathrm{MAP}$ se dirige à mucosa do intestino e associa-se ao tecido linfoide local, as placas de Peyer. Na região onde ocorreu a instalação da bactéria, decorre a fagocitose e a multiplicação de MAP no interior dos macrófagos, resultando na formação de um granuloma (Hines et al., 1995). Esse infiltrado crônico de macrófagos na lâmina própria determina a atrofia das vilosidades intestinais, sendo o responsável pela má absorção dos nutrientes (ELLINGSON et al., 2003). Por meio dos macrófagos, as bactérias se disseminam para outros órgãos, podendo ser verificada a presença do agente no epidídimo, sêmen, glândulas acessórias elinfonodos (Ayele et al., 2004). Em ovinos acometidos, são encontradas na mucosa intestinal frequentemente edemaciação, coloração avermelhada e aparência granular, mas que, raramente, aquela se apresenta ulcerada. Essas lesões acometem o segmento terminal do íleo, mas podem-se estender para o jejuno e o duodeno (Clarke, 1997). KhodaKaram TAFTI; RASHIDI (2000) relataram que as lesões encontradas em caprinos podem se manifestar de forma leve, com a mucosa intestinal opaca e espessa, até a forma grave com corrugações e edema da mucosa do intestino terminal associado ao comprometimento dos linfonodos mesentéricos. As lesões macroscópi- cas frequentemente são insuficientes para determinar a infecção pelo MAP, devendo ser associadas à sua análise histopatológica.

Os ovinos e caprinos podem apresentar duas formas patológicas distintas de lesões no intestino: paucibacilar ou tuberculoide multibacilar ou lepromatosa. Na forma paucibacilar, as lesões são caracterizadas por pequenos granulomas compostos por células epitelioides, circundados por linfócitos, com pouca ou nenhuma micobactéria, sendo essa forma caracterizada pelo aumento da resposta imune celular. A forma multibacilaré caracterizada por acúmulo de macrófagos preenchidos por grande quantidade de micobactérias, com aumento da resposta imune humoral (CLARKE; LitLLE, 1996; RAdOstits et al., 2002).

Em caprinos, podem-se classificar as lesões encontradas como: i) Focais: formadas por pequenos granulomas com abundância de macrófagos levemente corados pela HE (CORPA et al., 2000); ii) Multibacilar difusa: enterite granulomatosa difusa e linfadenite com numerosos macrófagos epiteliais distribuídos na mucosa do íleo e jejuno; iii) Linfocítica difusa: apresenta enterite granulomatosa difusa e linfadenite, mas diferentemente da multibacilar difusa, as células apresentam linfócitos com poucos macrófagos epitelióides e células gigantes com pouca ou nenhuma micobactéria e; iv) Difusa mista: enterite granulomatosa difusa com grande quantidade de linfócitos, plasmócitos, macrófagos epitelioides e células gigantes (CORPA et al., 2000; KHEIRANDish et al., 2009).

As lesões histológicas de enterite granulomatosa em caprinos são semelhantes às observadas em outras espécies, contudo, podem ainda manifestar degeneração axonal isquiática e do plexo dos nervos braquiais, amiloidose dos glomérulos renais, adrenais e glândula mamária (CHIODINI et al., 1984; BARKER et al., 1993). Verifica-se frequentemente que o grau de lesão intestinal encontrado em pequenos ruminantes não está associado com as manifestações clínicas. No entanto, estas manifestações estão substancialmente relacionadas com a carga de micro-organismos presentes nos macrófagos em determinadas áreas do intestino (ClarKe, 1997). KHEIRANDish et al. (2009) identificaram a presença de linfangite granulomatosa e macrófagos epitelioides contendo grande quantidade de micobactéria nos vasos linfáticos, inferindo que a disseminação de MAP por via linfática é possível. Nesse mesmo estudo, a presença de arterite granulomatosa e a formação de trombos com grande quantidade de macrófagos epitelioides nos linfonodos mesentéricos e na submucosa do intestino também sustentam a disseminação hematógena do agente.

Embora se tenha conhecimento da possibilidade de isolamento de MAP pelo sangue de animais infectados, em um estudo recente foi verificado que, 
de 53 ovinos infectados, apenas em quatro amostras de sangue foi possível obter culturas positivas. Essa difícil obtenção de isolados bacterianos limita a utilização de hemoculturas para o diagnóstico. Em parte esse fato pode ser explicado, pois observa-se que os animais com a forma paucibacilar da doença frequentemente desenvolvem uma bacteremia intermitente. Assim, as hemoculturas somente poderiam ser obtidas com amostras de sangue provenientes de animais que apresentem a doença na forma avançada, em média um ano após a infecção (BowER et al., 2011).

MAP é dita como uma bactéria fastidiosa para o crescimento "in vitro". Os meios para cultivo podem ser líquidos, como o caldo Middlebrook 7H9, ou sólidos que incluem Lowenstein-Jensen, LowensteinJensen modificado e meio Herrold gema de ovo (Herrol's Egg Yolk Medium - HEYM) (WHIPPLE et al., 1991). Independentemente do meio usado para o cultivo, todos exigem a suplementação com micobactina J (THORel et al., 1990), um composto que auxilia na captação de ferro pelo micro-organismo. Apesar do seu crescimento "in vivo" ser relativamente rápido, "in vitro" este é extremamente lento, sendo necessárias aproximadamente 12 a 16 semanas de incubação a $37^{\circ} \mathrm{C}$ para o surgimento das primeiras colônias (Collins et al., 1993).

A morfologia das colônias de MAP é bem característica, mas pode apresentar algumas variações de acordo com o meio de cultura utilizado (ColLINS, 2003). Em meio sólido HEYM, elas são pequenas, medindo entre 1 a 2 mm (GRANT, 2005), geralmente apresentam coloração branca, lisas e convexas, enquanto que em Middlebrook elas tornam-se mais rugosas (Collins, 2003).

Em alguns isolados de MAP, Collins et al. (1990) constataram diferenças fenotípicas e genotípicas provenientes de caprinos, ovinos e bovinos, subdividindo-os em cepas C (catlle) ou bovina e cepas $S$ (sheep) ou ovinas, segundo seus respectivos hospedeiros. Resultados semelhantes foram encontrados por BAUERFEIND et al. (1996), onde o tempo para o surgimento das colônias em meio sólido permitiu a subdivisão dos isolados em dois grupos principais: de crescimento rápido, verificado entre seis e 12 semanas e de crescimento lento, acima de 16 semanas. Cada um desses grupos também apresentou relação com seu respectivo hospedeiro. Culturas de crescimento rápido foram observadas em bovinos e caprinos, enquanto as de crescimento lento exclusivamente em ovinos. STEVENSON et al. (2002) verificaram que os isolados poderiam ser referenciados de acordo com suas características fenotípicas (tempo de crescimento) e moleculares (pulsed field gel electrophoresis-PFGE) e não em relação a seus hospedeiros preferenciais. Assim, passou-se a chamar de tipo I os isolados S, e tipo II os isolados C. Após três anos, utilizando a mesma técnica molecular, De JuAN et al. (2005) verificaram diferenças significativas nas análises filogenéticas de isolados caprinos, os quais permitiram incluir um novo isolado, chamado tipo III ou intermediário. Esse isolado foi assim denominado, pois apresentava perfil de PFGE intermediário às cepas do tipo I e II, mas as características fenotípicas de crescimento eram extremamente lentas, demonstrando maior proximidade com as cepas do tipo I.

As bases para identificação molecular em isolados de MAP estão sustentadas principalmente em $15 \mathrm{ou}$ 20 cópias da sequência do elemento de inserção (IS), denominado IS900 (BANNANTINE et al., 2002). Contudo, ENGLUND et al. (2002) identificaram IS900 em isolados de outras micobactérias, tal como Mycobacterium cookii. As colônias desta bactéria cresceram após três semanas de incubação, nas quais a temperatura ótima de crescimento foi de $30^{\circ} \mathrm{C}$, diferindo de MAP que apresenta temperatura ótima de $37^{\circ} \mathrm{C}$ (ENGLUND et al., 2002), e tempo de incubação acima de 12 semanas (Whitlock et al., 1989). A identificação de IS900 em outras micobactérias compromete os diagnósticos quando sustentados exclusivamente por essa sequência de inserção. Desse modo, trabalhos que apresentem amostras positivas para IS900 são confirmados pelo sequenciamento do amplicon e/ ou pelo isolamento de MAP e/ou pela amplificação de outras sequências gênicas (ENGLUND et al., 2002; CARvalho et al., 2009). Alguns autores identificaram efetividade no diagnóstico para o locus do gene f57 e locus 255 (MöBIUs et al., 2008), demonstrando que a associação de f57 e/ ou locus 255 com o IS900 seria uma alternativa para maior especificidade dos resultados. Dessa forma, autores têm direcionado sondas tanto para o locus do gene f57 como para o IS900 no diagnóstico de MAP, determinando alta efetividade ao utilizar a associação desses locus na comprovação do agente em amostras histológicas (RoccA et al., 2010). A utilização de técnicas moleculares, como a reação em cadeia da polimerase (PCR), permite a detecção da doença nas fases iniciais da infecção, que é importante considerando o controle da transmissão (NIELSEN; ToFT, 2008).

$\mathrm{O}$ advento do sequenciamento do genoma de MAP cepa K-10 (LI et al., 2005) possibilitou o surgimento de diferentes técnicas e genes-alvo para o diagnóstico direto do agente. Contudo, métodos indiretos também são amplamente empregados para o diagnóstico de MAP. O teste alérgico intradérmico baseia-se na inoculação de um extrato proteico de MAP, chamado Johnina, na prega ano-caudal ou pescoço de animais suspeitos. Esta técnica foi inicialmente utilizada no diagnóstico da paratuberculose, mas, devido apresentar baixa especificidade e muitas reações cruzadas com outras micobactérias (CHIODINI et al., 1984), não esta mais sendo empregada. Atualmente, tem-se preferido utilizar três testes para 
detecção de anticorpos contra MAP em animais acometidos, a reação de fixação do complemento (FC), teste de imunodifusão em gel de agarose (IDGA) e ensaio imunoenzimático (ELISA) (HARRIS; BARLETTA, 2001). Todos os testes apresentam considerável especificidade, no entanto, ELISA é o teste sorológico de eleição no controle da paratuberculose em rebanhos por ser de baixo custo, rápido e acurado (MANNING; CollinS, 2001) podendo apresentar maior especificidade em relação aos demais testes. A utilização de antígenos heterólogos de Mycobacterium phlei permitiu a adsorção de anticorpos inespecíficos e a redução de reações cruzadas em relação aos demais testes (SOCKETT et al., 1992). No entanto, o uso dessas técnicas torna-se efetiva apenas em estádios avançados de infecção, onde se tem a maior produção de anticorpos (HARRIS; BARLETTA, 2001).

Embora se tenha diferentes métodos de diagnóstico da paratuberculose, o cultivo coprológico, apesar de suas limitações em relação ao longo tempo de crescimento efacilidade de contaminação, aindaé o "padrão ouro" no diagnóstico da paratuberculose (Collins et al., 1993).

As técnicas adequadas para o diagnóstico da doença nos rebanhos tornam-se ainda mais importantes quando se têm relatos da possível infecção de MAP em humanos, suspeitando-se de estar relacionada com a doença de Crohn (DC). Esta se trata de uma inflamação crônica do intestino humano que acomete predominantemente o íleo e o cólon (CROHN et al., 1932), resultando em perdas de proteínas, síndrome da má absorção e esteatorreia (ELLINGSON et al., 2003). Devido não apenas às similaridades clínicas, mas também histopatológicas encontradas em humanos com enterite granulomatosa crônica e animais com paratuberculose, inferiu-se em 1913 uma mesma teoria causal para as duas doenças (DAlziel, 1913).

No entanto, existem estudos que não correlacionam MAP com a DC (ELLINGSON et al., 2003) e outros que obtiveram resultados positivos para essa correlação (RoccA et al., 2010). Essa falha na deteç̧ão pode estar relacionada à baixa quantidade de MAP nos tecidos e à capacidade do micro-organismo alterar a estrutura de sua parede celular, modificando antígenos de superfície que interferem nos resultados de diferentes técnicas de diagnóstico (Rocca et al., 2010). Mesmo assim, ainda não está clara a real importância da bactéria na patofisiologia da doença em humanos, nem os fatores que poderiam efetivamente contribuir para o surgimento da DC. Como inúmeros trabalhos têm demonstrado a presença de MAP em leite cru de bovinos, ovinos e caprinos (SingH; ViHAN, 2004; NebBIa et al., 2006; Nielsen et al., 2008; CARvalHo et al., 2009), suspeita-se que o leite possa ser um possível veiculador do agente para os humanos. Além do leite cru, alguns trabalhos investigaram o efeito da pasteurização sobre o leite contendo grandes concentrações de MAP. Autores relataram a sobrevivência de MAP após a pasteurização, embora não exista um consenso sobre quais as concentrações de MAP presentes no leite cru seriam inativadas pelas atuais condições de pasteurização (GRANT et al., 2002; Ayele et al., 2005; ElLINGSON et al., 2005). Nesse aspecto, entende-se que o controle da paratuberculose nos rebanhos leiteiros bovinos e de pequenos ruminantes deve ser mais efetivo, instituindo medidas preventivas à saúde pública e animal.

As perdas econômicas em rebanhos de ruminantes variam consideravelmente de acordo com o país. No Brasil, ainda não se têm dados quantificando as reais perdas produtivas de rebanhos acometidos pela paratuberculose, embora já tenham sido calculados os prejuízos da doença em alguns países. Nos Estados Unidos da América, Oтт et al. (1999) verificaram perdas nos rebanhos bovinos leiteiros entre 200 a 250 milhões de dólares por ano. Em relação aos prejuízos econômicos em rebanhos de pequenos ruminantes, Bushetal.(2006)identificaram, na Austrália, perdas médias acima de 13 mil dólares fazenda/ano.

Nos últimos anos, a detecção da paratuberculose em pequenos ruminantes domésticos tem sido referenciada como importante objeto de estudo em diferentes países (DjønNE et al., 2003; KRUZE et al., 2006; NebBia et al., 2006; EstÉvez-Denaives et al., 2007; IKONOMOPOUlos et al., 2007; Coelho et al., 2008; OliveIRA et al., 2010), principalmente pois há indícios de relações com a saúde pública. A doença é distribuída mundialmente, sendo uma ameaça à produção ovina mundial. Por esse motivo, alguns países como a Austrália passaram a desenvolver, nos rebanhos, programas de controle da paratuberculose ovina (AlLwORTH; KENNEDY, 2000). Em relação à doença nos rebanhos caprinos, ainda se têm limitadas informações em comparação a outros rebanhos, possivelmente devido à inferior representatividade daquelas em números de animais, nos países com desenvolvimento da indústria bovina (Juste; PEREZ, 2011). Mas este quadro está sendo modificado, pois é observado que o crescimento do efetivo de animais e o aumento da capacidade produtiva em diferentes países têm contribuído para a crescente representatividade econômica e comercial dos rebanhos caprinos.

Atualmente, não existe um tratamento efetivo para a paratuberculose e muitos medicamentos não são aprovados para o uso na pecuária (HARRIS; BARLETTA, 2001). Alguns antimicrobianos eventualmente são utilizados apenas para prolongar a vida de animais com alto valor zootécnico, mas os custos do tratamento são elevados e pouco gratificantes (HARRIS; BARLetTA, 2001). Tem sido relatado, ainda, quea antibioticoterapia não promove a cura completa 
dos animais infectados devido à inacessibilidade da droga às bactérias presentes no interior dos macrófagos, placas de Peyer e outras células da mucosa intestinal (Cocitoet al.,1994). Por esses motivos, ainda é indicado que animais positivos sejam retirados do rebanho e sacrificados.

Apesar de alguns países como a Noruega (SAXEGAARD; FodSTAD, 1985) e a Austrália (WINDSOR, 2006) obterem bons resultados no controle da paratuberculose pela vacinação, ainda não se tem completa efetividade na proteção contra a doença. Como a vacina reduz os sinais clínicos e a quantidade de MAP liberado pelas fezes (Juste; Perez, 2011), ela pode diminuir a incidência da infecção nos rebanhos pela redução da contaminação ambiental e controlar as manifestações clínicas associadas às perdas econômicas (AYELE et al., 2001). Embora a imunidade protetora induzida pela vacinação ainda seja pobremente compreendida, sugere-se que ela estimule a resposta imune mediada por células (HARris; BARLETTA, 2001).

A vacinação caprina nos países com programas de controle da doença geralmente é realizada com base nos mesmos critérios históricos empregados nos ovinos, nos quais o uso de vacinas vivas ou mortas permitiu relativo controle nos rebanhos. Contudo, a maior suscetibilidade dos caprinos à tuberculose e à paratuberculose compromete a efetividade dos programas em regiões onde ambas as doenças estão presentes (Juste; PeREZ, 2011). Assim, embora se tenha vantagens na utilização de vacinas, principalmente em ovinos, existem países e estados que não permitem sua utilização, pois esta é capaz de interferir em resultados de testes imunológicos e promover alterações nos resultados do teste da intradermoreação tuberculínica, utilizado no controle e erradicação da tuberculose (Muskens et al., 2002). Nestas circunstâncias, as melhores estratégias devem ser direcionadas às melhorias das medidas de biossegurança e de manejo para reduzir as chances de exposição de animais em seus momentos mais suscetíveis (Juste; Perez, 2011).

Como visto, a paratuberculose ovina e caprina aindaé pouco estudada em todo o mundo, no entanto, é verificado que o agente circula nos rebanhos. Esse quadro de carência de informações determina uma desvantagem econômica e comercial aos produtores brasileiros, pois a falta de um diagnóstico efetivo e o limitado conhecimento da real circulação do agente nos rebanhos pode resultar em expressivas perdas na produção leiteira, refugo precoce de animais e, futuramente, poderá vir a ser uma barreira para a exportação de produtos e subprodutos desses rebanhos. Sua contribuição para os impactos econômicos e a possível correlação com a DC instigam o aprimoramento e o desenvolvimento de técnicas mais rápidas, sensíveis e efetivas para o diagnóstico nos rebanhos brasileiros. Técnicas moleculares, como nested-PCR, estão sendo ajustadas para o diagnóstico de MAP em leite cru de caprino no Laboratório de Doenças Bacterianas da Universidade Federal de Viçosa (UFV). Através da agregação desses resultados com outras pesquisas, será possível identificar cepas de MAP circulantes nos rebanhos com maior rapidez e eficácia permitindo elaboração de planejamentos políticos de controle e prevenção da doença, bem como a garantia de maior qualidade e inocuidade de seus produtos.

\section{REFERÊNCIAS}

ACYPRESTE, C.S.; JULIANO, R.S.; RIVEIRA, F.E.B.; SILVA, L.A.F.; FIORAVANTI, M.C.S.; FILHO, F.C.D. Uso da técnica do ELISA indireto na detecção de anticorpos anti-Mycobacterium paratuberculosis em vacas em lactação. Ciência Animal Brasileira, v.6, p.41-45, 2005.

ALLWORTH, M.B.; KENNEDY, D.J. Progress in national control and assurance programs for ovine Johne's disease in Australia. Veterinary Microbiology, v.77, p.415-422, 2000.

AL-MAJALI, A.; JAWASREH, K.; NSOUR, A.A. Epidemiological studies on foot and mouth disease and paratuberculosis in small ruminants in Tafelah and Ma'an, Jordan. Small Ruminant Research, v.78, p.197-201, 2008.

ANIMAL AND PLANT HEALTH INSPECTION SERVICE (U.S.) . Johne's Disease on U.S. Dairies, 1991-2007 APHIS Info Sheet. 2008. Disponível em: <http://www.aphis.usda.gov/animal_health/nahms/ dairy/downloads/dairy07/Dairy07_is_Johnes.pdf>.

AYELE, W.Y.; MACHACKOVA, M.; PAVLIK, I. The transmission and impact of paratuberculosis infection in domestic and wild ruminants. Veterinary Medicine Czech, v.46, p.205-224, 2001.

AYELE, W.Y.; BARTOS, M.; SVASTOVA, P.; PAVLIK, I. Distribution of Mycobacterium avium subsp. paratuberculosis in organs of naturally infected bull-calves and breeding bulls. Veterinary Microbiology, v.103, p.209-217, 2004.

AYELE, W.Y.; SVASTOVA, P.; ROUBAL, P.; BARTOS, M.; PAVLIK, I. Mycobacterium avium subspecies paratuberculosis cultured from locally and commercially pasteurized cow's milk in the Czech Republic. Applied and Environmental Microbiology, v.71, n.3, p.1210-1214, 2005.

BANNANTINE, J.P.; BAECHLER, E.; ZHANG, Q.; LI, L.; KAPUR,V. Genome scale comparation of Mycobacterium avium subsp. paratuberculosis with Mycobacterium avium subsp. avium reveals potential diagnostic sequences. Journal of Clinical Microbiology, v.40, p.1303-1310, 2002. 
BARKER, I.K.; VAN DREUMEL, A.A.; PALMER, N. The alimentary system. In: JUBB, K. V. F.; KENNEDY, P. C.; PALMER, N. (Ed.) Pathology of domestic animals. San Diego: Academic Press, 1993. v.2. p.247-252.

BAUERFEIND, R.; BENAZZI, S.; WEISS, R.; SCHLIESSER, T.; WILLEMS, H.; BALJER, G. Molecular characterization of Mycobacterium paratuberculosis isolates from sheep, goats and cattle by hybridization with a DNA probe to insertion element IS900. Journal of Clinical Microbiology, v.34, p.1617-1621, 1996.

BERGEY, D.H.; HARRISON, F.C.; BREED, R.S.; HAMMER, B.W.; HUNTOON, F.M. Bergey's manual of determinative bacteriology. Baltimore;: Williams and Wilkins, 1923. 442p.

BOELAERT, F.; WALRAVENS, K.; BIRONT, P.; VERMEERSCH, J.P.; BERKVENS, D.; GODFROID, J. Prevalence of paratuberculosis (Johne's disease) in the Belgian cattle population. Veterinary Microbiology, v.77, p.269-281, 2000.

BOWER, K.L.; BEGGA, D.J.; WHITTINGTON, R.J. Culture of Mycobacterium avium subspecies paratuberculosis (MAP) from blood and extra-intestinal tissues in experimentally infected sheep. Veterinary Microbiology, v.147, p.127-132, 2011.

BUSH, R.R.; WINDSOR, P.A.; TORIBIO, J.A. Losses of adult sheep due to ovine Johne's disease in 12 infected flocks over a 3-year period. Australian Veterinary Journal, v.84, n.7, p.246-253, 2006.

CARVALHO, I.A.; SILVA JUNIOR, A.; CAMPOS, V.E.B.; MOREIRA, M.A.S. Detection of Mycobacterium avium subspecies paratuberculosis by polymerase chain reaction in bovine milk in Brazil. Journal of Dairy Science, v.92, p.5408-5410, 2009.

CHIODINI R.J. The history of paratuberculosis (Johne's disease). A review of the literature 1985-1992. Providence (RI): International Association of Paratuberculosis; 1993. $658 \mathrm{p}$.

CHIODINI, R.; VAN KRUININGEN, H.; MERKAL, R. Ruminant paratuberculosis (Johne's disease): the current status and future prospects. Cornell Veterinarian, v.74, p. 218-262, 1984.

CLARKE, C.J. The pathology and pathogenesis of paratuberculosis in ruminants and other species. Journal of Comparative Pathology, v.116, p.217-261, 1997.

CLARKE, C.J.; LITTLE, D. The pathology of ovine paratuberculosis: gross and histological changes in the intestine and other tissues. Journal of Comparative Pathology, v.114, p.419-437, 1996.

COCITO, C.; GILOT, P.; COENE, M.; KESEL, M.; POUPART, P.; VANNUFFEL, P. Paratuberculosis. Clinical Microbiology Reviews, v.7, p.328-345, 1994.
COELHO, A.C.; PINTO, M.L.; COELHO, A.M.; RODRIGUES, J.; JUSTE, R. Estimation of the prevalence of Mycobacterium avium subsp. paratuberculosis by PCR in sheep blood. Small Ruminant Research, v.76, p.201-206, 2008.

COLLINS, M. T. Update on paratuberculosis: 1. Epidemiology of Johne's disease and the biology of Mycobacterium paratuberculosis. Irish Veterinary Journal, v.56, n.11, p.565-574, 2003.

COLLINS, D. M.; GABRIC, D.M.; DE LISE, G.W. Identification of two groups of Mycobacterium paratuberculosis strains by Restriction Endonuclease Analysis and DNA hybridization. Journal of Clinical Microbiology, v.28, p.1591-1596, 1990.

COLLINS, D.M.; STEPHENS, D.M.; DE LISLE, G.W. Comparison of polymerase chain reaction tests and faecal culture for detecting Mycobacterium paratuberculosis in bovine faeces. Veterinary Microbiology, v.36, p.289-299, 1993.

CORPA, J.M.; GARRIDO, J.; GARCÍA MARÍN, J.F.; PÉREZ, V. Classification of lesions observed in natural cases of paratuberculosis in goats. Journal of Comparative Pathology, v.122, n.4, p.255-265, 2000.

COSTA, J.C.M.; PIERI, F.A.; SOUZA, C.F.; ESPESCHIT, I.F.; FELIPPE, A.G.; SANTOS, G.M.; TOBIAS, F.L.; SILVA JÚNIOR, A.; MOREIRA, M.A.S. Levantamento sorológico de Mycobacterium avium subesp. paratuberculosis em bovinos leiteiros no estado do Espírito Santo. Arquivo Brasileiro de Medicina Veterinária e Zootecnia, v.62, n.6, p.1491-1494, 2010.

CROHN B.B.; GINZBURG, L.; OPPENHEIMER, J. Regional ileitis. Journal of the American Medical Association, v.99, p.1232-1239, 1932.

DACORSO FILHO, P.; CAMPOS, I.O.N.; FARIA, J.F.; LANGENEGGER, J. Doença de Johne (paratuberculose) em bovinos nacionais. Arquivos do Instituto Biologia Animal, v.3, p.129-139, 1960.

DALZIEL, T.K. Chronic interstitial enteritis. British Medical Journal, v.2, p.1068-1070, 1913.

DE JUAN, L.; MATEOS, A.; DOMÍNGUZ, L.; SHARP, J.M.; STEVENSON, K. Genetic diversity of Mycobacterium avium subspecies paratuberculosis isolates from goats detected by pulsed-field gel electrophoresis. Veterinary Microbiology, v.106, p.249-257, 2005.

DIMARELI-MALLI, Z. Detection of Mycobacterium avium subsp. paratuberculosis in milk from clinically affected sheep and goats. International Journal of Applied Research in Veterinary Medicine, v.8, n.1, p.44-50, 2010.

DJØNNE, B.; JENSEN, M.R.; GRANT, I.R.; HOLSTAD, G. Detection by immunomagnetic PCR of Mycobacterium avium subsp. paratuberculosis in milk from dairy goats in Norway. Veterinary Microbiology, v.92, p.135-143, 2003. 
DRIEMEIER, D.; CRUZ, C.E.F.; GOMES, M.J.P.; CORBELLINI, L.G.; LORETTI, A.P.; COLODEL, E.M. Aspectos clínicos e patológicos da paratuberculose em bovinos no Rio Grande do Sul. Pesquisa Veterinária Brasileira, v.19, n.3/4, p.109-115, 1999.

DUPONT, O. Primeiro relato da doença de Johne's no Brasil [Nota] do Jornal do Commercio, (Rio de Janeiro), de 5 de novembro, 1915. p.8

ELLINGSON, J.L.E.; BREES, D.; CHEVILLE, N.F. Absence of Mycobacterium avium subspecies paratuberculosis components from Crohn's disease intestinal biopsy tissues. Clinical Medicine \& Research, v.1, n.3, p.217-226, 2003.

ELLINGSON, J.L.; ANDERSON, J.L.; KOZICZKOWSKI, J.J.; RADCLIFF, R.P.; SLOAN, S.J.; ALLEN, S.E.; SULLIVAN, N.M. Detection of viable Mycobacterium avium subsp. paratuberculosis in retail pasteurized whole milk by two culture methods and PCR. Journal of Food Protection, v.68, n.5, p.966-972, 2005.

ENGLUND, S.; BÖLSKE, G.; JOHANSSON, K.E. An IS900-like sequence found in a Mycobacterium sp. other than Mycobacterium avium subsp. paratuberculosis. FEMS Microbiology Letters, v.209, n.2, p.267-271, 2002.

ESTÉVEZ-DENAIVES, I.; HERNÁNDEZ-CASTRO, R.; TRUJILLO-GARCÍA, A.M.; CHÁVEZ-GRIS, G. Detection of Mycobacterium avium subsp. paratuberculosis in goat and sheep flocks in Mexico. Small Ruminant Research, v.72, p.209-213, 2007.

FONSECA, L.F.L.; SANTOS, M.V.; PEREIRA, C.C.; OLIVAL, A.A.; HIENEMANN, M. B.; RICHTZENHAIN, L.J. Identificação da presença de anticorpos contra Mycobacterium paratuberculosis em rebanhos leiteiros do Estado de São Paulo. Arquivos do Instituto Biológico, São Paulo, v.66, p.122, 1999. Trabalho apresentado no CONGRESSO BRASAILEIRO DE BUIATRIA, 3., 1999, São Paulo. Resumo 011.

GRANT, I.R. Zoonotic potential of Mycobacterium avium ssp. paratuberculosis: the current position. Journal of Applied Microbiology, v.98, p.1282-1293, 2005.

GRANT, I.R.; BALL, H.J.; ROWE, M.T. Incidence of Mycobacterium paratuberculosis in bulk raw and commercially pasteurized cows' milk from approved dairy processing establishments in the United Kingdom. Applied and Environmental Microbiology, v.68, n.5, p.2428-2435, 2002.

HARRIS, N.B.; BARLETTA, R.G. Mycobacterium avium subsp. Paratuberculosis in Veterinary Medicine. Clinical Microbiology Reviews, v.14, n.3, p. 489-512, 2001.

HINES, M.E.; KREEGER, J.M., HERRON, A.J. Mycobacterial infections of animals: pathology and pathogenesis. Laboratory Animal Science, v.45, p.334-351, 1995.
IKONOMOPOULOS, J.; BALASKAS, C.; KANTZOURA, B.; FRAGIADAKI, E.; PAVLIK,I.; BARTOS, M.; LUKAS, J. C.; GAZOULI, M. Comparative evaluation of positive tests to Mycobacterium avium subsp. paratuberculosis in clinically healthy sheep and goats in South-West Greece using molecular techniques, serology, and culture. The Veterinary Journal, v.174, p.337-343, 2007.

JOHNE, H.A.; FROTHINGHAM, L. Ein eigenthumlicher fall von tuberkulose beim rinde, [A peculiar case of tuberculosis in a cow]. Deutsche Zeitschrift für Tiermedizin und Vergleichende Pathologie, v.21, p.438-454, 1895.

JUSTE, R.A.; PEREZ, R.A. Control of paratuberculosis in sheep and goats. Veterinary Clinics of North America: Food Animal Practice, v.27, p.127-138, 2011.

KHEIRANDISH, R.; KHODAKARAM TAFTI, A.; HOSSEINI, A. Classification of lesions and comparison of immunohistochemical and acid fast staining in diagnosis of naturally occurring paratuberculosis in goats. Small Ruminant Research, v.87, p.81-85, 2009.

KHODAKARAM TAFTI, A.; RASHIDI, K. The Pathology of Goat Paratuberculosis: Gross and Histopathological Lesions in the Intestines and Mesenteric Lymph Nodes. The Journal of Veterinary Medical Science, v.47, p.487-495, 2000.

KRUZE, J.; SALGADO, M.; PAREDES, E.; MELLA, A.; COLLINS, M.T. Goat paratuberculosis in Chile: first isolation and confirmation of Mycobacterium avium subspecies paratuberculosis infection in a dairy goat. Journal of Veterinary Diagnostic Investigation, v.18, p.476-479, 2006.

LAMBETH, C.; REDDACLIFF, L.A.; WINDSOR, P.; ABBOTT, K.A.; McGREGOR, H.; WHITTINGTON, R.J. Intrauterine and transmammary transmission of Mycobacterium avium subsp paratuberculosis in sheep. Australian Veterinary Journal, v.82, n.8, p.504-508, 2004.

LAMONT, E.A.; BANNANTINE, J.P.; ARMIÉN, A.; ARIYAKUMAR, D.S.; SREEVATSAN, S. Identification and characterization of a spore-like morphotype in chronically starved Mycobacterium avium subsp. paratuberculosis cultures. PLoS One, v.7, n.1, p.1-10, 2012.

„LARSEN, A.B.; MERKAL, R.S.; CUTLIP, R.C. Age of cattle as related to resistance to infection with Mycobacterium paratuberculosis. American Journal of Veterinary Research, v.36, n.3, p.255-257, 1975.

LI, L.; BANNANTINE, J. P.; ZHANG, Q.; AMONSIN, A.; MAY, B.J; ALT, D.; BANERJI, N.; KANJILAL, S.; KAPUR, $\mathrm{V}$. The complete genome sequence of Mycobacterium avium subsp. paratuberculosis. Proceedings of the National Academy of Sciences of the United States of America (PNAS), v.102, p.12344-12349, 2005. 
MAINAR-JAIME, R.C.; VÁZQUEZ-BOLAND, J.A. Factors associated with seroprevalence to Mycobacterium paratuberculosis in small-ruminant farms in the Madrid region (Spain). Preventive Veterinary Medicine, v.34, p.317-327, 1998.

MANNING, E.J.; COLLINS, M.T. Mycobacterium avium subsp. paratuberculosis: pathogen, pathogenesis and diagnosis. Revue Scientifique et Technique, v.20, n.1, p.133-150, 2001.

MEDEIROS, J.M.A.; GARINO JUNIOR, F.; ALMEIDA, A.P.; LUCENA, E.A.; RIET-CORREA, F. Paratuberculose em caprinos e ovinos no estado da Paraíba. Pesquisa Veterinária Brasileira, v.32, n.2, p.111-115, 2012.

MÖBIUS, A.; HOTZEL, H.; RAßBACH, A.; KÖHLER, $\mathrm{H}$. Comparison of 13 single- round and nested PCR assays targeting IS900, ISMav2, f57 and locus 255 for detection of Mycobacterium avium subsp. paratuberculosis. Veterinary Microbiology, v.126, p.324333, 2008.

MOTA, R.A.; PEIXOTO, P.V.; YAMASAKI, E. M.; MEDEIROS, E. S.; COSTA, M. M.; PEIXOTO, R. M.; BRITO, M. F. Ocorrência de paratuberculose em búfalos (Bubalus bubalis) em Pernambuco. Pesquisa Veterinária Brasileira, v.30, n.3, p.237-242, 2010.

MUSKENS, J.; ZIJDERVELD, F.; EGER, A.; BAKKER, D. Evaluation of the long-term immune response in cattle after vaccination against paratuberculosis in two Dutch dairy herds. Veterinary Microbiology, v.86, n.3, p.269-278, 2002.

NEBBIA, P.; ROBINO, P.; ZOPPI, S.; DE MENEGHI, D. Detection and excretion pattern of Mycobacterium avium subspecies paratuberculosis in milk of asymptomatic sheep and goats by Nested-PCR. Small Ruminant Research, v.66, p.116-120, 2006.

NIELSEN, S.S.; TOFT, N. Ante mortem diagnosis of paratuberculosis: A review of accuracies of ELISA, interferon-y assay and faecal culture techniques. Veterinary Microbiology, v.129, p. 217-235, 2008.

NIELSEN, S.S.; TOFT, N. A review of prevalences of paratuberculosis in farmed animals in Europe. Preventive Veterinary Medicine, v.88, p.1-14, 2009.

NIELSEN, S. S.; BJERRE, H.; TOFT, N. Colostrum and milk as risk factors for infection with Mycobacterium avium subspecies paratuberculosis in Dairy Cattle. Journal of Dairy Science, v.91, p.46104615, 2008.

OLIVEIRA, D.M.; RIET-CORREA, F.; GALIZA, G.J.N.; ASSIS, A.C.O.; DANTAS, A.F.M.; BANDARRA, P.M.; GARINO JUNIOR, F. Paratuberculose em caprinos e ovinos no Brasil. Pesquisa Veterinária Brasileira, v.30, n.1, p.67-72, 2010.
OTT, S.L.; WELLSB, S.J.; WAGNERA, B.A. Herd-level economic losses associated with Johne's disease on US dairy operations. Preventive Veterinary Medicine, v.40, p.179-192, 1999.

POESTER, F.P.; RAMOS, E.T. Infecção experimental em caprinos com Mycobacterium paratuberculosis de origem bovina. Ciência Rural, v.24, p.333-337, 1994.

PORTUGAL, M.A.S.C.; PIMENTEL, J.N.; SALIBA, A.M.; BALDASSI, L.; SANDOVAL, E.F.D. Ocorrência de paratuberculose no Estado de Santa Catarina. $O$ Biológico, São Paulo, v.4, p.19-24, 1979.

POZZATO, N.; CAPELLO, K.; COMIN, A.; TOFT, N.; NIELSEN, S.S.; VICENZONI, G.; ARRIGONI, N. Prevalence of paratuberculosis infection in dairy cattle in Northern Italy. Preventive Veterinary Medicine, v.102, p.83-86, 2011.

QUINN, P.J.; MARKEY, B.K.; CARTER, M.E.; DONNELLY, W.J.; LEONARD, F.C. Microbiologia veterinária e doenças infecciosas.Porto Alegre: Artmed, 2005. 512p.

RADOSTITS, O.M.; GAY, C.C.; BLOOD, D.C.; HINCHCLIFF, K.W. Clínica veterinária: um tratado de doenças dos bovinos, ovinos, suínos, caprinos e eqüinos. Rio de Janeiro: Guanabara Koogan, 2002. 1737p.

RAMOS, E.T.; POESTER, F.P.; CORREA, B.L.; OLIVEIRA, S.J.; RODRIGUES, N.C.; CANABARRO, C.E. Paratuberculose em bovinos no estado do Rio Grande do Sul. A hora Veterinária, v.6, n.34, p.28-32, 1986.

RISTOW, P.; MARASSI, C.D.; RODRIGUES, A.B.F.; OELEMANN, W.M.R.; ROCHA, F.; SANTOS, A.S.O.; CARVALHO, E.C.Q.; CARVALHO, C.B.; FERREIRA, R.; FONSECA, L.S.; LILENBAUM, W. Diagnosis of paratuberculosis in a dairy herd native to Brazil. The Veterinary Journal, v.174, n.2, p.432-434. 2007.

RIVERA, F.E.B. Levantamento sorológico utilizando-se a técnica de ELISA em rebanhos apresentando problemas reprodutivos. I. Enterite paratuberculose. Anais do I Encontro de Laboratórios de Diagnóstico Veterinário do Cone Sul, p.20-22. 1996

ROCCA, S.; CUBEDDU, T.; NIEDDU, A.M.; PIRINO, S.; APPINO, S.; ANTUOFERMO, E.; TANDA, F.; VERIN, R.; SECHI, L.A.; TACCINI, E.; LEONI, A. Detection of Mycobacterium avium spp. paratuberculosis (Map) in samples of sheep paratuberculosis (Johne's disease or JD) and human Crohn's disease (CD) using liquid phase RT-PCR, in situ RT-PCR and immunohistochemistry. Small Ruminant Research, v.88, p.126-134, 2010.

SAXEGAARD, F.; FODSTAD, F.H. Control of paratuberculosis (Johne's disease) in goats by vaccination. Veterinary Record, v.116, p.439-441, 1985.

SILVA, N.M. Estudos sobre a paratuberculose. IV. Infecção experimental de ovino com Mycobacterium 
paratubeculosis de origem bovina. Pesquisa Agropecuária Brasileira, v.3, p.285-289, 1968.

SINGH, S.V.; VIHAN, V.S. Detection of Mycobacterium avium subspecies paratuberculosis in goat milk. Small Ruminant Research, v.54, p.231-235, 2004.

SOCKETT, D.C.; CONRAD, T.A.; THOMAS, C.B.; COLLINS, M.T. Evaluation of four serological tests for bovine paratuberculosis. Journal of Clinical Microbiology, v.30, n.5, p.1134-1139, 1992.

STEVENSON, K.; HUGHES, V.M.; DE JUAN, L.; INGLIS, N.F.; WRIGHT, F.; SHARP, J.M. Molecular characterization of pigmented and nonpigmented isolates of Mycobacterium avium subsp. paratuberculosis. Journal of Clinical Microbiology, v.40, p.1798-1804, 2002.

ST-JEAN, G.; JERINGAN, A.D. Treatment of Mycobacterium paratuberculosis infection in ruminants. Food Animal Practice, v.7, p.793-804, 1991.

STEHMAN, S.M.; SHULAW, W.P. Paratuberculosis (Johne's disease) in sheep and goats: recommendations for diagnosis and control. Saint Joseph, MO : United States Animal Health Association, Committee on Sheep and Goats, 1996.

SWEENEY, R.W.; WHITLOCK, R.H.; ROSENBERGER, A.E. Mycobacterium paratuberculosis cultured from milk and supramammary lymph nodes of infected asymptomatic cows. Journal of Clinical Microbiology, v.30, p.166-171, 1992a.

SWEENEY, R.W.; WHITLOCK, R.H.; HAMIR, A.N.; ROSENBERGER, A.E.; HERR, S.A. Isolation of Mycobacterium paratuberculosis after oral inoculation in uninfected animals. American Journal of Veterinary Research, v.53, p.1312-1314, 1992b.

THOREL, M.F.; KRICHEVSKY, M.; LEVY-FREBAULT, V.V. Numerical taxonomy of mycobactin-dependent mycobacteria, emended description of Mycobacterium avium, and description of Mycobacterium avium subsp. avium subsp. nov., Mycobacterium avium subsp. paratuberculosis subsp. nov., and Mycobacterium avium subsp. silvaticum subsp. nov. International Journal of Systematic Bacteriology, v.40, p.254-260, 1990.

THORNE, J.G.; HARDIN, L.E. Estimated prevalence of paratuberculosis in Missouri, USA cattle. Preventive Veterinary Medicine, v.31, p.51-57, 1997.

TIMMS, V.J.; GEHRINGER, M.M.; MITCHELL, H.M.; DASKALOPOULOS, G.; NEILAN, B.A. How accurately can we detect Mycobacterium avium subsp. paratuberculosis infection? Journal of Microbiological Methods, v.85, p.1-8, 2011.

TWORT, F.W.; INGRAM, G.L.Y. A method for isolating and cultivating Mycobacterium enteritidis chronicae pseudotuberculosae bovis johne and some experiments on the preparationof a diagnostic vaccine for pseudotuberculosae enteritis of bovines. Proceedings of the Royal Society of London. Series B. Biological Sciences, v.84, p.517-543, 1912.

WHIPPLE, D.L.; CALLIHAN, D.R.; JARNAGIN, J.L. Cultivation of Mycobacterium paratuberculosis from bovine fecal specimens and a suggested standardized procedure. Journal of Veterinary Diagnostic Investigation, v.3, p.368-373, 1991.

WHITLOCK, R.H.; ROSENBERGER, A.E.; SPENCER, P.A. Laboratory culture techniques for Johne's disease: a critical evaluation of contamination and incubation times. Proceedings - Annual Meeting of the United States Animal Health Association, v.93, p.382-386, 1989.

WHITTINGTON, R.J.; MARSHALL, D.J.; NICHOLLS, P.J.; MARSH, I.B.; REDDACLIFF, L.A. Survival and dormancy of Mycobacterium avium subsp. paratuberculosis in the environment. Applied and Environmental Microbiology, v.70, n.5, p.2989-3004, 2004.

WINDSOR, P. Research into vaccination against ovine Johne's disease in Australia. Small Ruminant Research, v.62, p.139-142, 2006.

Recebido em 3/8/11

Aceito em 10/7/12 